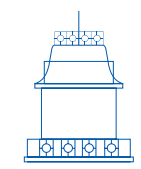

ARTÍCULOS

DE INVESTIGACIÓN

\title{
La verdad del cuerpo. Heidegger y la ambigüedad de lo corporal*
}

\author{
Ángel Xolocotzi Yáñez \\ Facultad de Filosofía, Benemérita Universidad Autónoma de Puebla, Puebla, México \\ E-mail: angel.xolocotzi@gmail.com
}

Recibido: 30 de abril de 2019 | Aprobado: 15 de julio de 2019

https://doi.org/10.17533/udea.ef.n61a09

Resumen: Ampliamente conocidos son los señalamientos realizados en Ser y tiempo por Martin Heidegger en torno al contraste entre la corporalidad pensada modernamente con base en una mezcla de cuerpo-alma, de raigambre cartesiana, y la corporalidad existenciaria a partir del Ser-en-el-mundo del Dasein. Después de ello y con pocas alusiones en algunas de sus lecciones, la tematización mayor en torno al cuerpo se remonta a los Seminarios de Zollikon. El presente artículo busca nuevas vías de tematización a partir de lo que Heidegger piensa como ambigüedad de la verdad en las diversas versiones de la conferencia "De la esencia de la verdad. La verdad del cuerpo dejaría ver al cuerpo en su errar como Körper y, por otro lado, en tanto misterio como Leib. Tal perspectiva permite una comprensión no unilateral del cuerpo y a la vez abre las posibilidades para pensarlo desde el Ser-en-el-mundo, tal como Heidegger había anunciado en diversos momentos de su obra.

Palabras clave: ex-sistencia, corporalidad, misterio, errar, dejar-ser

* El presente texto parte de una serie de preocupaciones planteadas en "Cuerpo, mundo y vida. Heidegger en perspectiva", conferencia presentada en las II Jornadas Nacionales de la Sociedad Iberoamericana de Estudios Heideggerianos (SIEH), realizadas los días 6 y 7 de diciembre de 2018, en la Agremiación Docente Universitaria Marplatense, Mar del Plata, Argentina.

Cómo citar este artículo:

Xolocotzi Yáñez, Á. (2020). La verdad del cuerpo. Heidegger y la ambigüedad de lo corporal. Estudios de Filosofía, 61, 125-144. https://doi.org/10.17533/udea.ef.n61a09

\section{OPEN 2 ACCESS}

Estud.filos n. ${ }^{0}$ 61. Enero-junio de 2020 | pp. 125-144 | Universidad de Antioquia | ISSN 0121-3628 | ISSN-e 2256-358X 


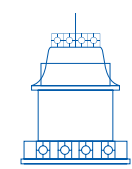

ARTÍCULOS

DE INVESTIGACIÓN

\title{
The truth of the body. Heidegger and the ambiguity of the bodily
}

\begin{abstract}
Martin Heidegger's remarks in Being and time on the contrast between the modernly thought corporeality based on a mixture of soul-body, of Cartesian roots, and the existential corporeality from the being-in-the-world of Dasein are widely known. After that, the major thematization on the body goes back to the Zollikon Seminars. This article looks for new ways of understanding the body based on what Heidegger considers as the ambiguity of truth in the various versions of the lecture "Of the essence of truth". The truth of the body would allow to understand the body in its erring as Körper and, on the other hand, in as much mystery as Leib. Such a perspective allows a non-unilateral understanding of the body and at the same time opens the possibilities for thinking about it from the Being-in-the-world, as Heidegger had announced it at various moments of his work.
\end{abstract}

Keywords: ex-sistence, corporeality, mystery, erring, let-being

\section{Ángel Xolocotzi Yáñez}

Doctor en filosofía por la Albert-Ludwigs-Universität de Friburgo, Alemania. Actualmente es profesor de tiempo completo de la Benemérita Universidad Autónoma de Puebla (México). Ha sido becario del KAAD, DAAD, Alexander von Humboldt-Stiftung (Alemania), O'Gorman Grant (Columbia University) y del Programa de estancia de doctores y tecnólogos (Universidad Complutense de Madrid-Grupo Santander). Forma parte del Sistema Nacional de Investigadores de México (nivel III) y participa en múltiples Comités Científicos como el del Heidegger-Jahrbuch. Tiene en su haber más de cien conferencias y ponencias, tres traducciones de Heidegger, así como once libros coordinados y otros diez de su autoría. Actualmente funge como director de la Facultad de Filosofía y Letras de la BUAP.

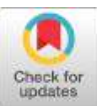




\section{Introducción}

En uno de los apuntes redactados por Medard Boss en 1963 y publicado en la primera versión de los Seminarios de Zollikon, ${ }^{1}$ se anota una respuesta al reproche de Sartre a Heidegger en torno a la cuestión del cuerpo:

Cuando Jean Paul Sartre reprocha a Martin Heidegger que éste ha tratado mal al cuerpo, este "mal trato" tiene dos razones:

1) El tratamiento de los fenómenos del cuerpo es completamente imposible sin un desarrollo suficiente de los fundamentos del existenciario ser-en-el-mundo.

2) Aún no hay una descripción suficiente, utilizable, del fenómeno del cuerpo, es decir, que sea vista desde el ser-en-el-mundo (Heidegger, 2013, p. 240).

Sabemos que a partir de la tematización ontológica de Heidegger en torno al Dasein, Sartre derivará sus nociones de "en-si", "para-sí" y "en-situación". En el marco de la tercera parte de El ser y la nada, el pensador parisino dedicará el capítulo segundo a la cuestión del cuerpo. Ahí, aunque no lo mencione explícitamente, hay una interpretación divergente respecto de Heidegger en torno a la cuestión del cuerpo, ya que Sartre pensará éste, no ya desde el cuidado existenciario, sino desde la contingencia en tanto el ser humano se interpreta como tal, como una realidad contingente: "En este sentido, podría definirse el cuerpo como la forma contingente que la necesidad de mi contingencia toma" (Sartre, 1986, p. 336).

Aunque en Ser y tiempo se encuentra planteada la posibilidad de entender los modos fundamentales de ser, entre ellos el existir y, a partir de ahí, sus determinaciones como ser-en-el-mundo, en trabajos posteriores Heidegger busca tematizar la cuestión del ser, no ya a partir de sus modos, sino de su acontecer. ${ }^{2}$ Eso, como sabemos, significa una crítica al planteamiento previo que estaba determinado principalmente por la aclaración de sentido y, por lo tanto, por una visión que buscaba tematizar a partir de lo olvidado. Precisamente ahí se planteará la pregunta por el sentido del ser en tanto un retomar la pregunta olvidada. Aunque ya en la ontología fundamental se expongan inicialmente las determinaciones de tal olvido, será hasta finales de la década de los

1 Como sabemos, los Seminarios de Zollikon refieren centralmente a las sesiones que Heidegger sostuvo con médicos, psicólogos y científicos de 1959 a 1970, por lo general en la casa de Medard Boss en Zollikon, Alemania (Heidegger, 2013, pp. 18-19). Éste reunió algunos protocolos, apuntes y conversaciones con Heidegger, así como una selección epistolar, y lo publicó en 1987 bajo el título de Zollikoner Seminare. Sin embargo, en 2018 se publicó el volumen 89 de la Gesamtausgabe de Heidegger con el mismo título, editado por Peter Trawny. Se trata de un volumen diferente debido a que en éste se incluyen fundamentalmente escritos de Heidegger no publicados en la versión de Boss. Para distinguir ambos textos aquí nos referiremos a la edición de Boss como "primera versión".

2 Una visión del paso de la ontología fundamental al pensar ontohistórico la proporcionan en este respecto Xolocotzi (2011) y Xolocotzi Et al. (2014). 
20 cuando Heidegger abrirá la posibilidad de tematizar no sólo el olvido de la pregunta por el ser, sino el olvidar mismo. De esa forma acaece un giro que conduce a hablar de la verdad del ser.

Las últimas décadas de publicaciones e interpretaciones sobre la obra heideggeriana dejan ver que sus tematizaciones pueden mostrarse explícitamente al ser desarrolladas en lo escrito o implícitamente al deslindarse de una propuesta concreta de la tradición metafísica. Esta vía negativa puede hacer evidente el asunto tratado sólo a partir de la recolección de elementos dispersos en la crítica respectiva. El problema del cuerpo no ha sido la excepción, ya que el "olvido" o el "mal trato" en la ontología fundamental remite más bien a una separación de la propuesta cartesiana debido a que la posibilidad de pensar al cuerpo desde la existencia es confrontada por Heidegger de modo directo con el planteamiento moderno de Descartes. En el inicio auténtico de Ser y tiempo, es decir en el parágrafo 12,3 remite a ello, sin nombrarlo:

El estar-en tampoco puede, por consiguiente, ser ontológicamente aclarado mediante una caracterización óntica, de modo que se pudiera decir, por ejemplo: el estar-en un mundo es una propiedad espiritual, y la "espacialidad" del hombre es un modo de ser derivado de su corporalidad [Leiblichkeit], la que a su vez está siempre "fundada" en la corporeidad física [Körperlichkeit]. Al decir esto, volvemos a encontrar un estar-ahí juntas [zusammengestzt] de una cosa espiritual así constituida y de una cosa corpórea; con lo que el ser mismo del ente así compuesto viene a quedar enteramente oscuro (Heidegger, 2003, p. 82).

Sabemos que el inicio de su obra magistral, Ser y tiempo, parte de la tematización del ente al que le es accesible algo así como el ser. Si ese ente soy yo en cada caso, se tendrán que desplegar primero sus estructuras determinantes. Sin embargo, Heidegger confrontará el modo de ser de este ente en la cotidianidad con lo caracterizado en la tradición metafísica. A pesar de que la parte histórica de Ser y tiempo, la cual contenía una detallada destrucción de la ontología, no fue publicada, encontramos en la parte sistemática una directa confrontación con la determinación central del ente que pregunta a partir de la modernidad. Concretamente me refiero a la propuesta de Descartes al pensar al ser humano como una "mezcla de espíritu y cuerpo"*

3 Eso lo indica Heidegger en su último curso en Marburgo (Cf. 1990, p. 214).

4 De acuerdo con Descartes, el ser humano puede ser descrito a partir de tres conceptos centrales: el cuerpo, la mente (alma) y la unidad cuerpo-mente (véase la carta dirigida a la princesa Elisabeth que data del 28 de junio de 1643, en Descartes [2002]). Esto último se trata de una unidad sui generis irreductible a una de las posibles partes, lo aclara la famosa cita de la sexta meditación: "La naturaleza también me enseña, por medio de esas sensaciones de dolor, hambre, ser, etc., que yo no sólo estoy en mi cuerpo como el marinero en su nave, sino que estoy unido estrechísimamente y como mezclado con él [quasi permixtum], de tal manera que formo una sola cosa con él. Pues si no fuera así, cuando el cuerpo se lesiona, 
o, como señaló Heidegger en la cita, un "estar-ahí juntas" dos cosas: la espiritual o mental y la corpórea. ${ }^{5}$

La oscuridad del ser del ente mencionada por Heidegger radica en que, para él, la "sustancia" del ser humano no es la unidad mezclada de cuerpo y alma, sino la existencia. Aunque el análisis de Ser y tiempo es limitado al respecto, la primera crítica que el filósofo de la Selva Negra podría realizar en torno a la propuesta cartesiana es que, si bien el núcleo corporal lo constituyen las sensaciones, ${ }^{6}$ la unidad queda marcada por la independencia ontológica del cuerpo y del alma. El alma correspondiente al ser humano debería ser vista en tanto siente y el cuerpo en tanto afecta, mediante el sentir, al alma.

A pesar del carácter intencional de las sensaciones, éstas se entienden en un sentido estrecho respecto del alma y el cuerpo. No se trata del cuerpo meramente extendido ni del alma meramente pensante, sino del cuerpo-alma sentiente. El sentir no se entiende desde sí, sino que remite a lo determinante esencialmente para el cuerpo y para el alma: la extensión y el pensar. Así, al sentir, el alma tendría una extensión potencial y las sensaciones serían una modificación del pensar.

A partir de esto, la crítica a Descartes se apoyaría, pues, en que el modo de ser del ente que siente no se deja explicitar desde sí mismo, sino desde un modo de ser que le es ajeno: la extensión que corresponde a todo cuerpo y el mero pensar que correspondería a cualquier ser espiritual. ${ }^{7}$

Aunque Descartes busca enfatizar mediante las sensaciones el ámbito propiamente humano, los presupuestos que ahí yacen lo conducen a entender la unidad humana de cuerpo y alma como una especie de mezcla. Esto hace, de acuerdo con Heidegger (2003), que "el ser mismo del ente así compuesto" en esta determinación "qued(e) enteramente oscuro" (p. 82). Quizás por ello, el autor de Ser y tiempo no se detiene más en esta

yo, que no soy más que una cosa pensante, no sentiría dolor, sino que percibiría esta lesión con el puro entendimiento, como el marinero percibe con la vista si algo se rompe en su nave; y cuando el cuerpo necesita alimento o bebida, lo entendería expresamente en vez de tener confusas sensaciones de hambre y sed. Pues ciertamente estas sensaciones de sed, hambre, dolor, etc. no son más que ciertos confusos modos de pensar que surgen de la unión y de esa especie de mezcla de la mente con el cuerpo" (p. 74).

5 Aun cuando se haya una gama de problemas aquí, no es objeto del presente artículo profundizar al respecto puesto que la referencia a Descartes es de carácter introductorio y la investigación se enfocará en otros aspectos. Por ello, no nos detendremos en las diferencias entre espíritu, alma y mente.

6 De acuerdo con Descartes, la mente (alma) puede separarse del cuerpo, pero mediante ella pierde la posibilidad de las sensaciones [sensus]. Y precisamente una de las determinaciones del ser humano para Descartes es ser capaz de sentir, de tener sensaciones, como lo señala en la conocida carta a Regius: "Si hubiese un ángel en un cuerpo, él no sentiría como nosotros, sino que sólo percibiría los movimientos que pudiesen ser causados por los objetos externos, y con ello se diferenciaría de los seres humanos verdaderos" (Descartes citado por Schmidt, 2007, p. 38). De ese modo, las sensaciones no serían sólo algo accidental unido al cuerpo, sino que determinarían esencialmente al ser humano como cuerpo.

7 Aquí se nos presentan las siguientes preguntas: ¿cómo puede mezclarse el cuerpo, determinado fundamentalmente por la extensión, y la mente, determinada por el pensar? ¿Acaso el cuerpo se mentaliza y la mente se corporaliza? Una lectura cuidadosa muestra que en Descartes encontramos sólo una dirección de la mezcla, ya que únicamente la mente se mezcla con el cuerpo, no así el cuerpo con la mente, aunque sí haya una interacción recíproca, como en el caso de las emociones. El motivo, de acuerdo con Schmidt, yace en el proyecto cartesiano de alejar lo mental de todo tratamiento geométrico de los objetos de la naturaleza (2002, p. 38). 
cuestión y lleva a cabo cierto distanciamiento al respecto. Si la oposición inicial para Heidegger es aquella entre el ser-en-el-mundo y la mezcla espíritu-corporal, entonces a partir de tal confrontación se podrá vislumbrar la diferencia entre lo corporal del seren-el-mundo y lo corporal de la subjetividad, lo que de alguna manera daría elementos para una posible "fenomenología del cuerpo" desde esta perspectiva.

Si queremos reiterar la pregunta por el cuerpo a partir de Heidegger, la ontología fundamental proporciona un comienzo al desplegar la idea del ser-en-el-mundo en la dirección señalada. Tal intento ha sido rastreado ya en múltiples investigaciones, ${ }^{8}$ pero nuestra posición al respecto es indagar en un texto que no ha sido relacionado con el problema, como lo son las conferencias De la esencia de verdad, según las cuales, en nuestra clave interpretativa, ofrece una elucidación del cuerpo a raíz del problema de la verdad. Es decir, a partir de la tematización de la verdad del ser -al inicio de las diversas versiones de las conferencias-, se podrán obtener elementos de otra índole para abordar el cuerpo de una manera diferente. Ya que hasta el momento esto no ha sido desplegado en las lecturas heideggerianas sobre el cuerpo, el presente artículo busca contribuir a dicha tarea al tratar de pensar la verdad del cuerpo.

\section{La búsqueda del ser-verdadero}

Si se preguntara por un hilo conductor en la filosofía de Heidegger, sin muchos rodeos responderíamos: la pregunta por el ser. Sin embargo, la ingente obra heideggeriana bifurca su preguntar a partir del planteamiento de la pregunta por el sentido del ser o a partir del olvidar mismo del olvido. Lo primero, sabemos, remite a la ontología fundamental, mientras que lo último es pensado como la verdad del ser. A partir de la autocrítica a la ontología fundamental a finales de la década de los 20 y extendiéndose hasta principios de los años 40, nuestro autor mantiene un hilo conductor plasmado de forma concreta en las conferencias "De la esencia de la verdad", publicadas en 2016 en el marco de la Gesamtausgabe (GA 80.1). ${ }^{9}$ Estas versiones constituyen la base de lo que se planteará aquí.

Ahora bien, en la ontología fundamental la cuestión del ser es aprehendida a la luz de su sentido, no obstante, la inquietud por pensar la verdad del ser hunde sus raíces en las interpretaciones hechas a partir de Aristóteles en los albores filosóficos de Heidegger en Friburgo y Marburgo. ${ }^{10}$ A partir de ahí se obtiene una idea de verdad en

8 Varios autores proceden en esta dirección: Yuasa (1976, tesis doctoral), Wiedemann (1984), Lotz (2005), Johnson (2010), Sandu (2014) y Peters (2019). Asimismo, Cf. Derrida (1998; 2012), quien se acerca a la cuestión del cuerpo a partir del problema de la diferencia sexual (Geschlecht II) en Heidegger.

9 Se trata de más de una década de planteamientos alrededor del problema de la verdad, pues la primera versión de la conferencia data de julio de 1930 y la última versión fue publicada en 1943. La traducción del volumen 80.1 fue realizada por el presente autor de este artículo y está en proceso de publicación por parte del FCE; las citas referentes al volumen 80.1 en el presente texto corresponden a esa traducción.

10 No se trata de plantear un camino homogéneo que vaya del joven Heidegger al pensar ontohistórico. Sabemos que no es el caso. 
tanto estar-desocultado que permeará su trabajo hasta Ser y tiempo. Como se sabe, la aletheia griega, ya desplegada desde sus lecciones de Marburgo, indica que la verdad no es algo disponible de inmediato, sino aquello que debe ser ganado y cuya exigencia remite a su poder-ser-arrancado desde el ocultamiento. En su conferencia de 1923/24 "Dasein y ser-verdadero" nuestro autor ya delineaba tres puntos en los que se hace valer la verdad: por un lado, lo ente puede estar encubierto a partir de los pareceres y habladurías de la cotidianidad; por otra parte, puede ser encubierto en tanto desconocido y, por último, pudo haber estado abierto y recaer en un disimulo que plantea incluso la falta de necesidad para preguntar nuevamente. Ante ello Heidegger establece un triple estar ocultado de lo ente que exige, de cierta forma, la intervención de la verdad:

1. en la medida en que el mundo está presente sólo en los pareceres primeros y próximos,

2. en la medida en que en muchos sectores de lo ente hay desconocimiento propio, todavía no se está familiarizado,

3. en la medida en que, lo que una vez fue propiamente despejado, se hunde nuevamente en el estar-ocultado mediante el dominio de la frase y de los conceptos desgastados por ella (Heidegger, 2016, p. 67).

Así, de acuerdo con Heidegger, la propuesta inicial griega, concretada de manera manifiesta por Aristóteles, buscaba destacar un modo de ser de lo ente: ser-verdadero. Aunque el ente se da de cierta forma, por ejemplo, en las habladurías cotidianas, no tendría de entrada una forma distinguida de presencia como lo es el hecho de estardesencubierto, de ser-verdadero. Tal desencubrir lo destaca Heidegger en el habla misma, en el logos. Se trata del habla reveladora que deja ser al ente en tanto verdadero.

Sin embargo, el desocultar y revelar señalan el papel de la verdad en la relación con los entes. Se trata de una lucha contra los pareceres, el desconocimiento y el disimulo. En cada caso el logos en tanto habla reveladora cumple un papel diferenciado. La lucha entre lo que se oculta y el desocultamiento condujo a Heidegger a preguntar por aquello que sustenta tales posibilidades. Nuestro autor busca pensar el movimiento que va desde lo ocultado hacia lo desocultado. Este movimiento se expresa inicialmente al pensar la aletheia como estar-desocultado, donde lo central es el movimiento de extirpación que ahí acaece. Al mismo tiempo destaca el acecho del ocultamiento para volver a caer en él. La verdad entonces no es algo definitivo ni establecido, sino un proceso constante que exige el movimiento de desocultar y revelar.

Simplemente vale la pena destacar que la inquietud por la verdad respecto del ser, el ser-verdadero, estaba ya presente desde las lecturas sobre Aristóteles. 


\section{De la potenciación de la esencia a la potenciación originaria de la esencia}

Lo planteado en las lecciones, seminarios y conferencias sobre Aristóteles en torno al ser-verdadero atraviesa las exposiciones de Ser y tiempo y es retomado de forma radical a finales de la década de los 20 mediante las diversas versiones de la conferencia "De la esencia de la verdad". "Se trata de al menos cinco versiones que pueden dividirse en dos grupos: aquellas que plantean el inicio y final del asunto, es decir, las versiones primera, cuarta y quinta; $y$, por otro lado, aquellas que constituyen el taller e intentos (fallidos) de despliegue de la cuestión, es decir, las versiones segunda y tercera. Si remitimos a la cuarta versión, que constituye el sedimento para la versión publicada en 1943 -la quinta-, encontramos que Heidegger busca llegar al problema del movimiento de la aletheia a raíz de la base que ella misma otorga, es decir la relación entre ocultamiento y desocultamiento.

Tal posibilidad se deja ver al partir de los pareceres en torno a la verdad misma. Como sabemos tales pareceres pueden mantenerse abiertamente en el sentido común o penetrar en la propia tradición filosófica. Precisamente la concepción común de verdad indica eso: la idea de que la verdad es una adecuación ${ }^{12}$ entre el pensar y la cosa, o una coincidencia entre la proposición y lo mentado en ella.

En estas posibilidades, Heidegger procede con base en el movimiento mismo de la verdad, es decir, a partir de la relación entre ocultamiento y desocultamiento. La posibilidad de los pareceres, de lo desconocido y de lo disimulado indica el papel de lo ocultado y a la vez la necesidad de lo desocultado, es decir, la exigencia de arrancar lo desocultado de lo ocultado mismo y mantener la cautela respecto de lo desocultado. Como ya anticipamos, al estar-desocultado corresponde también la misión de cuidar tal proceso y evitar caer nuevamente en lo ocultado.

Dado que la idea tradicional de la verdad está enmarcada en un esquema que impide verla como un proceso respecto de lo ocultado, lo que exige la tematización de éste, Heidegger da un paso más al preguntar ya no por la verdad sino por la esencia de la verdad.

De esta forma, en las versiones segunda y tercera de la conferencia, Heidegger plantea dos estadios, cada uno de ellos con tres etapas en el despliegue de la pregunta por la verdad a partir de su esencia. En el fondo se tratará de tematizar la esencialidad

11 La primera versión es la conferencia dictada en Karlsruhe el 14 de julio de 1930. La segunda versión fue leída en Bremen el 8 de octubre de 1930, mientras que la tercera se leyó en Marburgo el 5 de diciembre y en Friburgo el 11 de diciembre de 1930. La cuarta versión fue trabajada en otoño de 1934 y en Pentecostés de 1940. Finalmente, la quinta versión fue la publicada en Hitos en 1943 y retomada en el volumen 9 de la Gesamtausgabe (Cf. Heidegger, 2016, p. 549, GA 80.1).

12 Si bien la concepción tradicional del problema de la verdad se ha mantenido en términos de adecuación (adecuatio), en adelante, ateniéndome a la interpretación heideggeriana de la verdad y tomando en cuenta la traducción que ofrezco de las cuatro versiones de la conferencia "De la esencia de la verdad", la verdad será entendida en términos de concordancia. 
de la esencia de la verdad. En el marco del primer estadio, "la potenciación de la esencia" de la verdad (Wesensbemächtigung), Heidegger analiza en una primera etapa la comprensión común de la verdad a partir de la coincidencia y concordancia, es decir, lo conocido como verdad de la proposición y verdad de la cosa. En una segunda etapa se pregunta por la posibilidad interna del qué, del contenido, de la verdad entendida comúnmente. Ahí se plantea la necesidad del sostenimiento previo de la vinculación con aquello verdadero. La posibilidad de entender el coincidir o concordar que caracteriza a lo que podemos nombrar verdadero exige en tal comportamiento una medida que se constituya como directriz en la comparación. Así que inicialmente se trata de un donar y tomar medida (Massgeben y Massnehmen). Sin embargo, previo al patrón o directriz ceñido a alguna medida, Heidegger (2016) hace ver la necesidad de la vinculación entre lo comportado y el comportamiento en el coincidir o concordar. Por ello, inicialmente habla de un "sostenimiento previo de la vinculación" (Sichvorhalten von Verbindlichkeit) (Heidegger, 2016, p. 355). A partir de ahí se puede plantear la donación de medida y lo determinante del comportamiento respectivo.

Al tematizar esto, Heidegger detecta un problema: por un lado, se trata de sostenerse previamente en la vinculación para posibilitar la patencia del ente en el coincidir; pero a la vez debe haber ya algo patente para hablar de esa posible vinculación (Cf. Heidegger, 2016, p. 355). Con base en ello, nuestro autor plantea la pregunta “¿En qué se funda algo así como la concesión previa del vínculo?" (2016, p. 356). Sabemos que la respuesta aquí es la libertad.

A partir del cuestionamiento en torno a la relación entre los "momentos estructurales del comportamiento" (2016, p. 356), es decir, el dejar-ser-vinculante y el patentizar, Heidegger propone destacar el "fundamento de la posibilidad interna" (2016, p. 359) del contenido de la verdad, es decir, la libertad. Estas tres etapas constituyen el estadio preliminar en la pregunta por el conocimiento esencial de la verdad, al que Heidegger nombra "potenciación de la esencia" (2016, p. 359), como ya mencionamos. Antes bien, se tratará de avanzar precisamente hacia la esenciación de la esencia con el paso a la "potenciación originaria de la esencia" (Wesensermächtigung): "dejar a la esencia su esencialidad originaria" (2016, p. 360).

En este estadio encontramos también diversas etapas. La primera de ellas consiste en resguardar la esencia de la verdad frente a la autodefensa del sentido común. En ello se retoma el problema ya plateado en el primer estadio en su segunda etapa, a decir, el dejar-ser vinculante y la patencia. Así, Heidegger fortalece la estructura del patentizar al señalar que éste "debe dejar de antemano que lo ente sea siempre lo ente, que es y cómo es" (2016, p. 362). El patentizar remite pues a un originario dejar-ser lo ente.

Ahora bien, el análisis de la cuestión se aclara en este segundo estadio al disolver lo planteado en el primero, pues aquello que constituye el comportamiento no son dos elementos sino uno. Así, el dejar del dejar-ser-vinculante y el dejar-ser lo ente del patentizar remiten a un solo fenómeno: "El dejar-ser lo ente como tal, originariamente 
desocultante y patentizador, es desde sí el sostener previamente de la vinculación de lo ente en su ser" (Heidegger, 2016, p. 364).

\section{Libertad, ex-sistencia e insistencia}

De esta forma, el objetivo de Heidegger se dirige a aclarar lo que se mienta con "dejarser". Cabe destacar que el dejar-ser es de entrada desocultante, ya que se trata de la libertad: "Dejar-ser es por sí mismo, como tal, desocultante" (2016, p. 363) y "la libertad es este dejar-ser" (p. 364). Sin embargo, falta aclarar el tipo de relación que hay entre ambos aspectos. Nuestro autor despliega esto con base en un "primer y último atreverse" en donde un ente se levanta en medio de lo ente contra lo ente. Se trata pues de una "rebelión" que hace que el ente que se comporta retroceda ante lo ente para dejarlo-ser y en ello se sujete a sí mismo. Aquí ocurre pues un doble movimiento, el de la retención y el de la sujeción. ${ }^{13}$ Sabemos que la tradición moderna ha visto sólo un lado al tematizar la sujeción con base en el sujeto mismo y no ha logrado aprehender la retención (Verhaltenheit). En el comportamiento, el ente que se rebela se expone a lo ente y a la vez retrocede en la retención para dejar-ser lo ente. Esto es a lo que Heidegger llama libertad. Así, no se trata sólo del ser humano, sino de lo ente en sí, en donde el ser-humano está expuesto a lo ente al llevar a cabo la retención.

De esa forma, la libertad no es entendida como una propiedad del sujeto, sino como una forma de entender el dejar-ser de lo ente al ser desocultado en el comportarse que lleva a la rebelión de lo ente. Por ello, el estar-desocultado de la verdad tendrá un carácter de extracción a partir de lo ocultado.

Con esto se deja ver un despliegue de aquello que Heidegger había tematizado en Ser y tiempo respecto del Dasein y la existencia. Ahí se señalaba que la existencia es el modo de ser de este ente caracterizado como Dasein. Sin embargo, quedaba oscuro el hecho de hablar de modos de ser en donde la existencia sería uno entre otros. Heidegger ahora enfatiza que ex-sistir remite al hecho de que el ser humano ya está en la verdad, es decir que se expone y retiene lo ente al dejarlo-ser. ${ }^{14}$ Por ello entonces se da la vinculación con tal o cual ente.

Precisamente porque a la base yace el dejar-ser, ello implica la posibilidad de la no-verdad. Pero tanto el sentido común como la filosofía misma han colocado la pregunta por la no-verdad fuera de la pregunta por la verdad y con mayor razón por

13 La importancia de lo que Heidegger señala en las versiones intermedias de la conferencia "De la esencia de la verdad" yace en plantear un elemento más para diferenciar entre la propuesta metafísica que alcanza a ver la sujeción del ente que se comporta y que es interpretado como subjetividad y la posibilidad de desplegar al Dasein mismo como aquel ente que se expone y retrocede en la retención ante lo ente. Con ello Heidegger proporciona mayores elementos para diferenciar sujeto y Dasein.

14 Para diferenciar la "existencia" como modo de ser del Dasein en la ontología fundamental de la "ex-sistencia" como elemento determinante de la libertad del Dasein ante lo ente, Heidegger introduce el cambio de grafía mediante el guion. 
la esencia de la verdad. De forma complementaria se requiere girar la perspectiva y si la no-verdad no puede entrar en la esencia de la verdad, entonces se requiere de la inesencia de la verdad para comprender la esencia propia de la verdad. Por ello, el paso al segundo estadio, es decir, lo que Heidegger llama potenciación originaria de la esencia (Wesensermächtigung), exige no aprehender la no-verdad y la inesencia como meros opuestos, sino admitirla en el proceso de esenciación de la esencia de la verdad. Se trata de descubrir el carácter intrínseco de la inesencia en la esencia.

El dejar-ser ex-sistente y desocultante de la libertad que caracteriza a la esencia de la verdad remite al ente singular; no obstante, acaece necesariamente y de forma complementaria la patencia de lo ente en totalidad: "Donde está la libertad ex-sistente, es decir, donde ex-siste el Dasein, ahí acontece esta complementación” (Ergänzung) (Heidegger, 2016, p. 369). Tal "complementación" de lo ente en totalidad impera como lo indeterminado indeterminable, es decir, como un ocultamiento sobre lo ente como tal. Se trata pues de un ocultamiento en su totalidad. Así lo aclara Heidegger (2016) en la tercera versión de la conferencia De la esencia de la verdad: "El estar-ocultado no es una consecuencia tardía del desocultamiento en el sentido superficial, que sólo con el desocultamiento de lo ente todo ente sea patente, sino que más bien oculta el desocultar en sí -esto es en tanto dejar-ser lo ente en su totalidad" (p. 369). Y esto no es otra cosa que lo que llamará la posibilidad del misterio.

Anteriormente se indicó que ex-sistir significa ya estar en la verdad en tanto el Dasein no es otra cosa que aquel ente expuesto y que en medio de lo ente deja-ser al ente. Sin embargo, al dejar-ser al ente singular que comparece desocultándolo, el Dasein insiste respecto del ente ya que "el Dasein es ex-sistente [...] y porque exsistente es necesariamente insistente" (Heidegger, 2016, p. 371). Acaece a la vez el desocultamiento de lo ente en totalidad que devela la posibilidad de la no-verdad, en tanto se trata de lo ente en su no-estar-desocultado. Así, en cada desocultamiento de lo ente, el Dasein ex-sistente es abrumado por el estar-ocultado de lo ente en totalidad y a la vez es insistente respecto del desocultamiento del ente singular. En ello, como ya se dijo, radica la posibilidad del misterio. El ocultamiento de lo ente en totalidad a lo que alude el misterio tiene determinaciones fundamentales, como Heidegger indica en una anotación marginal: "Este ocultamiento es aún más antiguo, y sólo con respecto a él, porque es el primero, puede el desocultamiento ser de tal o cual ente" (2016, p. 369, nota 57).

Con todo, la "vasta masa de urgencias conocidas y emergencias identificables" (Heidegger, 2016, p. 317) conducen a que aquel ocultamiento primario sea olvidado y, continúa Heidegger: "de esta manera, el ser humano no sólo está dentro y con lo ente que acaba de ser patente, sino que se endurece a sí mismo como el único y realmente verdadero, insiste en el doble sentido del olvidarse y medirse" (p. 371). El 'estar dentro' del ser humano señala el hecho de comportarse en cada caso con el ente singular, insiste en su relación con él. Así, el Dasein es ex-sistente al estar expuesto y dejar-ser lo ente en totalidad y es insistente respecto del dejar-ser el ente respectivo. 
Con ello se puede ver entonces que el Dasein al ex-sistir no sólo está en la verdad sino más bien y de forma más originaria en la no-verdad. Ésta, como ya se indicó, constituye el sentido del no-estar-desocultado, la in-esencia de la verdad. Con lo ya desplegado se observa entonces que tal inesencia puede ser aprehendida en un sentido propio como misterio en tanto se mantiene en la esencia de la verdad o de forma impropia al caer en su nulidad. Y ahí, dice Heidegger, es donde surge el error (2016, p. 372).

El errar (Irren) de donde surge el error (Irrtum) se debe, de acuerdo con nuestro autor, a que la patencia de la insistencia nunca se empalma con la patencia de la ex-sistencia, sino que se da una relación de dependencia. La patencia de la insistencia depende de la patencia de la ex-sistencia. Con ello Heidegger deja ver que en todo comportamiento con el ente singular ocurre un doble movimiento que conduce a la interpretación de la verdad en un carácter ambiguo: por un lado, el Dasein al ex-sistir está expuesto a lo ente en totalidad y lo deja-ser. En ello se desoculta lo ente en totalidad, pero se oculta lo ente singular en el que el Dasein insiste. Así, acontece el juego de ocultamiento y desocultamiento. Al ex-sistir se desoculta lo ente en totalidad y se oculta el ente singular; al insistir se oculta lo ente en totalidad y se desoculta el ente singular.

\section{La ambigüedad del cuerpo}

Si retornamos a la problemática planteada inicialmente en torno al cuerpo, la ambigüedad de la verdad da elementos para una comprensión del fenómeno corporal mismo. Recordemos el protocolo del 11 de mayo de 1965 de la primera versión de los Seminarios de Zollikon en donde Heidegger sugiere dar un salto al problema del cuerpo (Cf. 2013, p. 138). De entrada, señala que el objetivo es Ilevar a cabo un acercamiento al fenómeno del cuerpo en donde no se hablaría de una solución, sino que ya se ganaría lo suficiente si se logra ver el problema (Cf. 2013, p. 139). El ejemplo inicial al respecto es un texto sobre la no-medición de la tristeza y la medición de las lágrimas. Heidegger enfatiza el hecho de que ni siquiera las lágrimas pueden ser medidas, sino en el mejor de los casos, un líquido y sus gotas. Ante la pregunta de si las lágrimas son algo somático o psíquico, Heidegger responde: "Ni lo uno ni lo otro" (2013, p. 139). El siguiente ejemplo que se menciona es sobre el ruborizarse de vergüenza e incomodidad. Ahí también se indica la imposibilidad de medir el rubor, aunque sí la rojez del rostro mediante el suministro sanguíneo, por ejemplo. En este caso se responde de la misma forma si se quiere definir la pertenencia del rubor al ámbito somático o psíquico. En estos casos como en otros fenómenos analizados respecto del cuerpo parece pues que el mencionado acercamiento no se concreta ni en lo somático ni en lo psíquico y que en tal 'ni lo uno ni lo otro' Heidegger quiere indicar otra posibilidad. Considero que tal posibilidad remite a la verdad del cuerpo.

La ambigüedad de la verdad lleva por un lado al predominio de cierta interpretación de la relación entre lo ocultado y lo desocultado que lleva al error en tanto pareceres 
(engaño), desconocimiento o disimulo de este; por otro lado, encontramos el misterio. El hecho de que tanto el error como el misterio provengan de la ambigüedad de la verdad conduce a la confusión, como bien señala en su conferencia de 1931 sobre la alegoría de la caverna de Platón: "Es por eso que el ser humano a menudo convierte lo que es un engaño en un misterio, y viceversa, considera que el misterio es un engaño" (Heidegger, 2016, p. 476).

De esto podemos obtener dos aspectos importantes: uno, la justificación de que Heidegger no haya hablado del cuerpo como tal, ya que éste, como modo de ser de un ente, remite a sus posibilidades interpretativas: engaño, desconocimiento, disimulación o misterio. El segundo, el hecho de hablar de confusión entre error (engaño) y misterio plantea elementos de la propia esencia de verdad, el errar, que pudiesen plantear la idea de una regresión a otras medidas determinantes.

Al respecto hay que indicar que la ambigüedad de la verdad del cuerpo se deja ver de entrada en la forma de nombrar. En alemán esto se hace transparente al hablar de Körper y Leib, asunto ampliamente trabajado por Edmud Husserl de quien Heidegger es deudor cuando habla precisamente de esta distinción fenomenológica del cuerpo. Grosso modo, el tratamiento husserliano sobre el cuerpo se expresa en tres etapas, por un lado, en Ideas $I^{15}$ donde el pensador pone de relieve el entrelazamiento entre cuerpo y conciencia; en un segundo momento en Ideas II, Husserl tematizará entonces la constitución del cuerpo propio desde la subjetividad trascendental haciendo expresa la distinción entre Körper y Leib: "El cuerpo, por ende, se constituye primigeniamente de manera doble: por un lado es cosa física, MATERIA, tiene su extensión a la cual ingresan sus propiedades reales, la coloración, lisura, dureza, calor, y cuantas otras propiedades materiales similares haya; por otro lado, encuentro en él, y SIENTO "en" él y "dentro" de él: el calor en el dorso de la mano, el frío en los pies, las sensaciones de toque en las puntas de los dedos" (Husserl, 2014, p. 185). Y no menos importante resulta el tratamiento hecho en la quinta de las Meditaciones Cartesianas. No así, a lo que apuntamos es precisamente a la apropiación de dicha distinción, con la cual Martin Heidegger a la luz de los Seminarios de Zollikon, discutirá la posibilidad del desocultamiento y ocultamiento como la ambigüedad del cuerpo mismo.

Como sabemos en español no contamos con dos términos de esa forma para referir al cuerpo, pero sí con la interpretación a la que remiten ellos. Aunque en la traducción de la primera versión de los Seminarios de Zollikon, se indica que se trata de "aprehender el fenómeno originario y derivado que en castellano se esconde en el término cuerpo

15 "Solo por su referencia de experiencia con el cuerpo se convierte la conciencia en realmente humana y animal, y solo por ello obtiene un lugar en el espacio de la naturaleza y en el tiempo de la naturaleza... solo mediante el enlace de la conciencia y el cuerpo en una unidad empíricamente intuitiva, natural, es posible algo así como una comprensión mutua entre los seres animales pertenecientes a un mundo, y que solo por ello cada sujeto cognoscente puede hallar el mundo en su plenitud, consigo y con los otros sujetos y a la vez reconocerlo como el mismo mundo circundante, perteneciente en común a él y a todos los demás sujetos" (Husserl, 2013, p. 201). 
y que en alemán se expresa en dos vocablos" (Heidegger, 2013, p. 10), en esta ocasión haré referencia a los dos vocablos para señalar la distinción aquí mencionada. Así, el Körper remite a aquello mensurable y objetivable que se tiene, mientras que Leib hace referencia al cuerpo que se es. En este sentido podríamos hablar del cuerpo que se tiene y el cuerpo que se es. Al preguntar por el cuerpo e interpretarlo como algo que se tiene, se parte de una idea de corporalidad general compartida con otros modos de ser, es decir, se trata de algo que está-ahí, de algo presente, que precisamente podría ser tenido. A partir de ello se abren posibilidades para el estudio del cuerpo en el ámbito de las ciencias naturales o en la medicina a través de la anatomía y fisiología, por ejemplo. Así, el cuerpo como Körper es problematizado en los Seminarios de Zollikon porque fundamentalmente en su estudio se lleva a cabo el desocultamiento del ente a partir de la insistencia del Dasein y así se permite el ocultamiento de la ex-sistencia en su estar expuesto a la totalidad de lo ente. En el estudio del cuerpo como ente singular se oculta pues la totalidad de lo ente, es decir, el mundo mismo. Para Heidegger eso justifica el hecho de que el cuerpo no se haya pensado desde el ser-en-el-mundo con lo que replicaba su respuesta al "mal trato" del cuerpo señalado por Sartre.

\section{Corporar como errar y como misterio}

La verdad del cuerpo, como Körper, indica lo ya señalado anteriormente, como noverdad impropia que en el marco del errar da pie al error. Si todo se interpreta a partir del Körper, ¿en qué medida ya ha desaparecido ahí la posibilidad del corporar mismo? Lo relacionado con éste es más bien medido, y así ya se ha donado y tomado medida, lo que no conduce a penetrar en su esencia. Se trata en el fondo de verlo en un carácter meramente entitativo. En los ejemplos señalados, al intentar medir las lágrimas, la tristeza o el dolor, desaparecen los fenómenos corporales como tales y erramos en su interpretación. Echamos de menos el cuerpo como tal para abordar aspectos que remiten a un mero estar-ahí de algo medible.

Así, el corporar puede ser visto en un sentido a partir de aquello que se desoculta inmediatamente, como lo sería el movimiento de mis manos al escribir estas líneas; sin embargo, en ello se oculta a la vez la ex-sistencia en tanto un estar-expuesto a lo ente en totalidad. El comportamiento respectivo desoculta mi cuerpo en lo inmediato, pero oculta la respectividad con lo ente en totalidad. Como vimos, la remisión única a lo insistente conduce al errar en tanto error; mientras que la remisión a lo existente nos lleva al misterio.

Ambas posibilidades del juego ocultamiento-desocultamiento pueden ser vistas también a partir de la diferencia ontológica. El errar remitiría, como ya señalamos a la positividad entitativa de lo medible. Es decir, al ámbito del dejar-ser patente. Mientras que el misterio abre la perspectiva de la apertura de ser que señala el dejarser vinculante. En otras palabras, se trata de la relación de lo óntico con lo ontológico. 
En un diálogo de Heidegger con Boss, se señala esto de la siguiente forma:

De todo lo que Sartre escribe, nada es verdadero. Más bien la totalidad de los rasgos ontológicamente esenciales de una cosa son visibles sólo a través de datos ónticamente descriptibles, como viceversa todos los datos ónticamente perceptibles están fundados en sus determinaciones ontológicas y son regidas por éstas, en tanto son. Los rasgos ontológicos y los hechos ónticos no pueden ser encontrados de manera separada, sino que siempre se entrelazan uno a otro (Gander, 1991, p. 125).

Si consideramos esto a la luz del asunto del cuerpo, éste no podría ser tomado simplemente como el lado 'óntico' del Dasein, sino que la corporalidad se aprehendería en el entrelazamiento ontico-ontológico que determina el modo de ser del Dasein como ex-sistencia. Si el cuerpo es visto sólo ónticamente, entonces estaríamos considerando únicamente la insistencia y no la ex-sistencia.

De acuerdo con Heidegger, el problema no es pues aprehender el cuerpo como tal, sino detectarlo desde el modo propio de ser del ente comprensor afectivo de ser, es decir, del ente ex-sistente. Al cuerpo óntico que puede ser descubierto corresponde pues la apertura de una corporalidad que puede ser aprehendida como fenómeno ontológico, es decir, no como un ente meramente descubierto sino más bien a partir del ser en su carácter aparente.

Si en la diferencia entre ser y ente se da también la diferencia en el modo de acceso, entonces, lo abierto del cuerpo ontológico no puede ser descubierto como un ente, sino que tiene carácter de ser y por ende se manifiesta en su retraimiento.

El retraimiento de los fenómenos ontológicos será ocasión de crítica al planeamiento filosófico central de Heidegger, tanto en la ontología fundamental como en el pensar ontohistórico. Sin embargo, en ese punto se halla la posibilidad de comprender la radicalidad de la propuesta como misterio. Si no se logra divisar el acceso propio a lo ontológico, ex-sistente, y se presupone un acceso óntico, insistente, entonces se mantiene la interpretación sobre la base positiva del descubrimiento de los entes, tal como ha trabajado gran parte de la metafísica occidental.

De esta forma, el "olvido" del cuerpo es expresión, pues, del olvido del ser. El ser ha sido olvidado porque no puede ser accesible solamente como positum entitativo. Asimismo, el cuerpo. Su aprehensión se ha limitado sólo a un camino en tanto tematización de algo extenso que simplemente está-ahí presente. Con todo, Heidegger enfatiza que mi cuerpo no es solamente lo presente que se tiene, sino también lo exsistente que se es.

Quizás el problema en el acceso a la corporalidad ontológica del ex-sistir sea aquello que evite que Heidegger hable de más en torno al cuerpo. Por ello se entiende la crítica que Sartre hará en términos de que Heidegger "haya escrito solamente seis líneas acerca del cuerpo en todo Ser y tiempo" (Heidegger, 2013, p. 337). Como se sabe, el filósofo de la Selva Negra simplemente responderá que lo corporal "es lo más difícil y que en aquel entonces no tenía más que decir al respecto" (2013, p. 337). 


\section{Cuerpo insistente y cuerpo extático}

A partir de lo ya desplegado desde Ser y tiempo, existir es un modo de ser cuya determinación fundamental yace en el carácter descentrado del ente que aparece. Esto será abordado bajo la idea de la estancia extática del Dasein, es decir, su estar siempre ya fuera de sí en tanto mera relación de ser. Si el Dasein es el lugar en donde acontece la diferencia ontológica, es decir el entrelazamiento de lo óntico y lo ontológico, entonces, decíamos, el cuerpo podría ser también interpretado como misterio desde el modo de ser correspondiente bajo la guía de la diferencia ontológica. En este caso se puede hablar pues de un cuerpo extático, cuya tematización logra ser destacada al ser confrontado con una visión meramente óntica del cuerpo en tanto extensión.

Si preguntamos por el corporar de una experiencia académica como podría ser la lectura de una ponencia, lo que se muestra es que en ese caso estoy sentado en la silla apoyándome en la mesa leyendo mi ponencia frente al público. Eso, como destaca Heidegger (2013) no puede ser entendido como "un estar ahí de un cuerpo sobre otro" (p. 160), como sería la silla y la mesa. Al concluir mi lectura, alguno de los asistentes podrá preguntar y en ese caso estaré a la escucha. Mi hablar y escuchar como el escuchar y hablar de los asistentes se da como diálogo que muestra el corporar del ser-en-el-mundo. Lo fuera de sí de tal corporar se deja ver en el hecho de que yo me dirijo a los asistentes y ellos me hablan al preguntar. La lectura que hago tiene en cuenta la escucha en la medida en que intento leer para ser comprendido con pausas y con pretensión de claridad, por lo menos acústica. Así, la lectura no es una cuestión mecánica como si se tratara de fonetizar solamente un determinado orden de palabras. Se trata de un evento corporal en el que está en juego mi ser-en-el-mundo en la situación respectiva. A partir del modo como abro mundo en ese evento académico es que se organiza el "ahí" de mi cuerpo, por ejemplo, al estar sentado y no moviéndome de un lado al otro del auditorio. Con ello lo que vemos es que mi cuerpo no se limita a estar sobre la silla apoyado en la mesa, sino que incluye el lenguaje al hablar y escuchar: "Oír y hablar, esto es, el lenguaje, en general, es siempre también un fenómeno corporal” (Heidegger, 2013, p. 160). ${ }^{16}$

Mi hablar y escuchar es tal en tanto corpora ahí. Sin embargo, este "estar ahí" es a su vez un estar allá al escuchar a alguien que pregunte o al leer mis páginas en la computadora o en el papel. Estoy ahí y allá precisamente porque mi modo de ser no es un mero estar-ahí-presente ${ }^{17}$ sino un ex-sistir, es decir un estar extático o fuera de sí expuesto a lo ente. El cuerpo está entonces fuera de sí al estar ahí y allá.

16 Para un análisis más detallado, se puede leer el capítulo "Habla, diferencia ontológica y ser-en-el-mundo" (Cf. Xolocotzi, 2018).

17 No se debe confundir el "estar ahí" o "estar allá" espacial en que se lleva a cabo el corporar del Dasein con el mero estar-ahí presente de un ente que no tiene el modo de ser de la existencia. Tal "estar-ahí" es la propuesta de Jorge Eduardo Rivera en su traducción del texto completo de Sein und Zeit (Heidegger, 2003) para traducir la "Vorhandenheit" que Heidegger atribuye a los entes teoréticamente accesibles y que ha sido el modo de ser privilegiado por la tradición metafísica occidental. 
Como vemos hay pues una diferencia en entender el cuerpo en tanto insistencia a partir de la entidad del ente que está-ahí, como mera positividad y entenderlo desde el ex-sistir como un estar en cada caso fuera de sí. Lo corporal, visto de esta forma, tiene entonces carácter de ser y por ende puede ser pensado, como decíamos, como relación fuera de sí, extática. Lo corporal pertenece al existir y mienta el misterio: "está codeterminado por mi ser-humano en el sentido de la estancia extática en medio del ente despejado" (Heidegger, 2013, p. 147).

Hablar del errar de la insistencia a partir del Körper o del misterio de la ex-sistencia a partir del Leib parecería plantear algo limitado que no proporciona mayores elementos para pensar filosóficamente la cuestión del cuerpo; empero, me parece que al respecto podríamos decir, por un lado, que no se trata de restricciones impuestas por alguna incapacidad de desarrollo, sino por el modo de donación del asunto a tratar. Es evidente que las investigaciones de la ciencia natural y la medicina en torno al cuerpo exigen la idea de cuerpo en tanto errar (engaño), es decir, que se requiere el punto de partida de lo que está ahí compartido con otras posibilidades para poder llevar a cabo un tratamiento o experimento que conduzca a un conocimiento de algunas regiones corporales objetivas. La mensurabilidad o las pruebas (o incluso las manipulaciones) en torno a los órganos remiten a criterios aplicables para diversas áreas, en donde, como sabemos ocurre la remisión sólo a tal parte u órgano y no a la totalidad del cuerpo, y mucho menos a la totalidad de lo ente. Se trata ahí del cuerpo que se tiene, tal como lo menciona en los Seminarios de Zollikon. Sin embargo, es un asunto necesario. Se trata de eso que hacemos al tomar antibióticos o medir los niveles de colesterol. Tanto el errar del cuerpo que se tiene como el misterio del cuerpo que se es indica pues que el cuerpo es ambiguo respecto de su verdad.

\section{Conclusión}

Cuando se ha pretendido escribir sobre el cuerpo a partir de Heidegger, la empresa parece ya de entrada estar condenada al fracaso. No obstante, el intento realizado aquí no se atiene a los esquemas acostumbrados, mas bien busca abrir posibilidades a partir de lo pensado en torno a la verdad y su esencia. Por ello, lo aquí desplegado ha intentado pensar la verdad del cuerpo, no a partir de su capa más exterior, sino a partir de su esencialidad, es decir, de aquel ámbito que no se colma con la anulación de lo que pareciera ser su alteridad. Así, una idea errada del cuerpo, en el sentido del errar, lo devela a partir de la insistencia con el ente, desocultándolo, pero a la vez ocultando lo ente en totalidad de la ex-sistencia. Podríamos decir que, al preguntar por la verdad del cuerpo en su esencialidad, lo que en la inmediatez es visto como ajeno y no esencial se constituye como determinante para entender la verdad del cuerpo en tanto misterio, es decir, a partir de la ex-sistencia en donde se desoculta lo ente en su totalidad, a saber, el mundo. En el misterio, el cuerpo puede ser visto a partir 
del ser-en-el-mundo en donde su inesencia, esa alteridad que parecía ajena, constituye esencialmente aquello que lo determina.

Conviene señalar que el mencionado juego entre ocultamiento y desocultamiento al pensar la verdad y, concretamente la verdad del cuerpo, se mantiene en la ambigüedad. Tal ambigüedad no es algo peyorativo, sino un intento por salir de una vía unilateral que privilegie un lado u otro. Ambos sentidos de cuerpo serían modos de verdad. Por eso, a partir de lo pensado por Heidegger no se podría atribuir simplemente un maltrato o descuido al cuerpo, sino en gran parte se trata de mantener en vilo la problemática con miras a su ambigüedad, es decir, su verdad. Con esto quizás se logre comprender que el mayor acercamiento que se puede lograr es precisamente a ese carácter ambiguo del cuerpo que en el fondo no es otra cosa que su verdad.

\section{Referencias}

Ciocan, C. (2008). The Question of the Living Body in Heidegger's Analytic of Dasein. Research in Phenomenology, 38(1), 72-89. https://doi.org/10.1163/156916408X262811

D’Angelo, D. (2012). Die Schwelle des Lebe-Wesens: Überlegungen zur Leibinterpretation Heideggers in der Nietzsche-Abhandlung. Studia Phaenomenologica, 12, 61-83. https:// doi.org/10.7761/SP.12.61

Derrida, J. (1998). Políticas de la amistad seguido de El oído de Heidegger. Madrid: Trotta.

Derrida, J. (2012). La mano de Heidegger (Geschlecht II), (M. Rivera Huntiel, Trad.). Nombres, Revista de Filosofía, 21(26), 7-50.

Descartes, R. (2002). Discurso del método y Meditaciones metafísicas (M. García Morente, Trad.). Madrid: Tecnos.

Espinet, D. (2016). Phänomenologie des Hörens. Eine Untersuchung im Ausgang von Martin

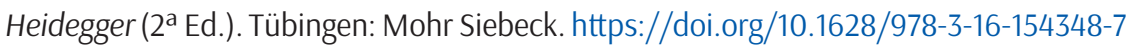

Gander, H. H. (Ed.). (1991). Von Heidegger her: Wirkungen in Philosophie, Kunst, Medizin. Frankfurt am Main: Vittorio Klostermann.

Heidegger, M. (1977). Sein und Zeit (1927). En F. -W. von Herrmann (Ed.), Gesamtausgabe (Vol. 2). Frankfurt am Main: Vittorio Klostermann.

Heidegger, M. (1990). Metaphysische Anfangsgründe der Logik im Ausgang von Leibniz. En K. Held (Ed.), Gesamtausgabe (Vol. 26). Frankfurt am Main: Vittorio Klostermann.

Heidegger, M. (2000). Hitos (A. Leyte \& H. Cortés, Trads.). Madrid: Alianza Editorial.

Heidegger, M. (2003). Ser y tiempo (J. E. Rivera, Trad.). Madrid: Trotta.

Heidegger, M. (2004). Wegmarken. En F.-W. von Herrmann (Ed.), Gesamtausgabe (Vol. 9). Frankfurt am Main: Vittorio Klostermann. 
Heidegger, M. (2006). Zollikoner Seminare (3a ed., M. Boss Ed.). Frankfurt am Main: Vittorio Klostermann.

Heidegger, M. (2013). Seminarios de Zollikon (2ª ed.). (Á. Xolocotzi, Trad.). México-Barcelona: Herder. Heidegger, M. (2016). Vorträge 1915-1932. En G. Neumann (Ed.), Gesamtausgabe (Vol. 80.1). Frankfurt am Main: Vittorio Klostermann.

Heidegger, M. (2017). Zollikoner Seminare. En P. Trawny (Ed.), Gesamtausgabe (Vol. 89). Frankfurt am Main: Vittorio Klostermann.

Husserl, E. (2002). Meditaciones cartesianas (A. Presas, Trad.) Madrid: Tecnos.

Husserl, E. (2013). Ideas relativas a una fenomenología pura y una filosofía fenomenológica. Libro I: Introducción general a la fenomenología pura (J. Gaos \& A. Zirión, Trads.). México: UNAM/FCE.

Husserl, E. (2014) Ideas relativas a una filosofía fenomenológica y una filosofía trascendental, Libro II: Investigaciones fenomenológicas sobre la constitución. (A. Zirión Trad.). México: FCE/UNAM.

Johnson, E. (2010). Der Weg zum Leib: Ontologie der Leiblichkeit anhand des Denkens Martin Heideggers. Würzburg: Königshausen \& Neumann.

Lotz, C. (2005). Vom Leib zum Selbst: kritische Analysen zu Husserl und Heidegger. FreiburgMünchen: Alber Reihe.

Nielsen, C. von, Steinmann, M. \& Töpfer, F. (Eds.). (2007). Das Leib-Seele-Problem und die Phänomenologie. Würzburg: Könighausen \& Neumann.

Peters, M. E. (2019). Heidegger's embodied others: on critiques of the body and 'intersubjectivity' in Being and Time. Phenomenology \& the Cognitive Sciences, 18(2), 441-458. https://doi. org/10.1007/s11097-018-9580-0

Sartre, J. (1986). El ser y la nada. México D.F.: Alianza.

Sandu, P.-G. (2014). Dasein, Raum und Leib - Eine Kritik der Existenzialanalyse von Sein und Zeit. Studia Universitatis Babes-Bolyai, Philosophia, 59(3), 17-33.

Schmidt, A. (2007). "Quasi permixtum". Die Einheit von Körper und Geist bei René Descartes. En C. von Nielsen, M. Steinmann \& F. Töpfer (Eds.), Das Leib-Seele-Problem und die Phänomenologie (pp. 35-51). Würzburg: Könighausen \& Neumann.

Steinmann, M. (2008). Die Offenheit des Sinns. Untersuchungen zu Sprache und Logik bei Martin Heidegger. Tübingen: Mohr Siebeck. https://doi.org/10.1628/978-3-16151331-2

Veysset, P. (2013). La confrontation Binswanger-Heidegger dans les Zollikoner seminare. Qu'est-ce qu'avoir un corps. In L'Évolution psychiatrique, 78(4), 583-597. https://doi.org/10.1016/j. evopsy.2013.06.002

Wiedemann, G. (1984). Zeitlichkeit contra Leiblichkeit. Eine Kontroverse mit Martin Heidegger. Frankfurt am Main: Lang. 
Xolocotzi Yáñez, Á., (2004). Fenomenología de la vida fáctica. Heidegger y su camino a Ser y tiempo. Barcelona-Ciudad de México: Plaza y Valdés-Universidad Iberoamericana.

Xolocotzi Yáñez, (2011). Fundamento y abismo. Aproximaciones al Heidegger tardío. Ciudad de México: Miguel Ángel Porrúa-BUAP.

Xolocotzi Yáñez, Gibu, R., Huerta, V. \& Veraza P. (2014). Heidegger. Del sentido a la historia. Madrid-Ciudad. de México: Plaza y Valdés-BUAP.

Xolocotzi Yáñez, (2014). Dasein, cuerpo y diferencia ontológica. En Á. Xolocoti \& R. Gibu (Coords.), Fenomenología del cuerpo y hermenéutica de la corporeidad (pp. 131-143). Madrid-Ciudad. de México: Plaza y Valdés-BUAP.

Xolocotzi Yáñez, \& Gibu, R. (Coords.) (2014). Fenomenología del cuerpo y hermenéutica de la corporeidad. Madrid-Cd. de México: Plaza y Valdés-BUAP.

Xolocotzi Yáñez, Á. (2018). Heidegger, lenguaje y escritura. Ciudad. de México: Fontamara.

Yuasa, S. (1976). Der Leib. Studien zu einer Phänomenologie des Leibes (Tesis doctoral inédita). Universidad de Colonia, Alemania. 